\title{
Impact of Responsible Leadership on Organizational Behaviour
}

\author{
Sankar Rajeev \\ Professor, Business Studies KL University, DCSMAT, WCBM, KL University, Vijayawada, Andhra Pradesh, India \\ E-Mail: 731.s.rajeev@gmail.com
}

\begin{abstract}
Employees have feelings, attitudes, values, moods and emotions which when directed in the desired manner leads to organizational effectiveness. One of the foremost contributions of a manger is leadership, because all organizations thrive on human resource as a vital factor. Success of a leader or ability to undertake risk management is an epitome of organization and its behavior, characterized by the leader, group and structure. Organizational environment thus created has evolved a dynamic condition which has given rise to a relatively innovative concept "Responsible leadership" considering maturity level of the group. This is not a theoretical framework but an approach to leadership. Responsible leadership advances the existing definitions of leadership and this research proposes to analyze the impact on organizational behavior.
\end{abstract}

Keywords: Responsibility, Leadership, Organizational Behavior, Emotion, Multi-Cultural Society

\section{INTRODUCTION}

Hawthorne experiments have shown the way for understanding organizational behavior as an important element for organizational effectiveness when supplemented by correct approach to leadership. When this moulds itself to the desired attitude with the aim of achieving the goal set, transforms itself to conscientious leadership. Hence it would not be an overstatement to consider leadership and organizational behaviour as correlated facets of business administration. Leadership concepts have changed over the time due to numerous factors some of which are the leaders, organization, and consideration of workers as a resource, rapid change in technology, market factors, customers, economic and political factors and time. Such a dynamic condition has given rise to a relatively new concept "Responsible leadership". A responsible leader has to understand the manifestation of these factors and aim at CSR as well. Alertness and awareness of responsibilities ensure that responsible leaders take decisions and are neither 'any action' or 'not to take a decision' types. They are those who take decisions after analyzing all factors and considering absolute inputs to deliberate the impact of the end result of their actions and decisions upon the stake holders. Rampant violation of ethical behaviour, persistent corporate scandals and hankering by business houses to amass wealth has resulted in growing discontentment and lack of faith in leaders making way for this concept, which is also a persistent demand amongst stakeholders in the industry.

Organizational behaviour is a field of study that looks into the effect individuals, groups, and structures have on behaviour within organization for the purpose of applying such knowledge towards improving organization's effectiveness. In a virtual organizational structure, its role is even more vital. There are three pillars of behaviour in an organization, which are the individuals, group and structure. The science of organizational behaviour was cultivated by applying general concepts to a situation, person or group. Its understanding has never been more critical to managers than in the present environment. Changes such as the rising use of technology, versatility of employment options has given new opportunities for workers. At the same time leaders are faced with the challenges of responding to economic pressures, globalization, volatility, uncertainty, complexity and ambiguity. These challenges urge managers to effectively use organizational behaviour concepts.

Critical factor of leadership is the ability to influence a group towards achievement of vision or set of goals. Responsible leaders address issues concerning the interest of stake holders which are to challenge the status quo, create visions of future, and inspire members to achieve the goal. Situational theory of leadership can be a close bet in such a scenario where there is a confluence of the concept of responsible leadership and organizational behaviour. Leader-member relationship may be robust when employees have an effective role in shaping their own job performance which is in tune to their developmental level. Research on software developers and their supervisor's shows that leader-member relationships have a stronger impact on employee performance and attitudes, when employees have higher levels of auto no my and a more internal locus of control. [EH Schein, Role of Founder in creating organizational culture" Organizational Dynamics (Summer 1983), pp 13- 18]

Organizations with dependable leaders are likely to be more profitable. Compared to a transactional or transformational leader, this approach tends to inspire the followers towards establishing goal by clarifying role and task requirements. Hence organizational effectiveness is an important take away. Ethics and leadership intersect at numerous places. Unethical leaders do tend to adopt a charismatic approach to accentuate their power over the subordinates and direct towards self-serving ends. The reason why ethical leaders support varied organizational behaviour is because of the reason that they are generally epitome of positive statements, like the famous Winston Churchill's victory speech during the Second World War. 
Another crucial aspect which is to be considered in this setting is that leadership is not value free.

Current analysis would attempt to concentrate on the impact of responsible leadership on organizational behaviour through a process of organizational commitments. Role of performance management for taking into account the commitment of organization or promoters in fostering emergence of such type of leadership is also considered to be reasoned by the fact that the role of responsible leaders in influencing employee attitudes and behaviour is an important feature of managing workers. As the internal antagonism is looked upon as a process of makeover to influence the way in which the employees' function in a global environment, the capability for collaborating with internal and external stake holders presupposes greater importance. In this research work we will also investigate the ability of responsible leadership to establish a hold of talent or prevent high labour turn over in this era of millennial which is characterized by rapid employee turnover. Attempt is also on to measuring the performance of this style of leadership keeping in mind the attainability where responsible leadership may not succeed every time as in the case of dominating charismatic battler or high performance oriented ruthless leader.

\section{LITERATURE REVIEW}

Objective of this study is to advance into recent phenomena of management which is the subject of responsible leadership consequent to the espousal of globalization world all over, with specific interest to its impact on organizational behaviour. For the literature review in order to preclude duplicity and incorporate recency, attempt was made to carry out bibliometric analysis taking a sample of 110 SSCI-indexed journals which were available. The period covered was from 19912018, where in liberalization was felt world all over. A total of 73 items published in these journals over the period were taken as sample with leadership as the domain. As the study progressed it was obvious that there has been a surge in the attempt to address the topic of responsible leadership from the results of person responsible, excerpt, and co-citation, factor analyses. Despite that, what was nonconforming is that the line of attack adopted was little bit biased on to the theoretical aspects of limited areas. In this discreet analysis the important topics that have till now been attempted are types of leadership, theories of leadership, emotional contagion, environmental challenges on leadership and functions of responsible leaders. Hence it was noticeable that the correlation between responsible leadership and organizational behaviour has not been till now attempted.

Stodgill (1950) highlighted leadership as one of the world's oldest concerns, as exemplified by Homer's book the Iliad and the Greek heroes. Vibrancy of responsible leadership as a research topic both in academia and in the business, world cannot be wished away. The reason for such a movement is primarily the rapid progress towards a global village and connectedness in the society. Caused by this there is a growing awareness on managers responsibilities and ethical behaviour [Si \&Ye; 2016]. This would be supported by the observation that corporate and managerial responsiveness have been under public examination more than ever before [Pfeiffer, 2015]. Leadership can be considered as "the process of influencing the activities of an organized group in its efforts toward goal setting and goal achievement". [Stodgil, 1950, pp3] So, it has been seen that all stakeholders are striving to address mutually supporting attributes of the complex society, increasing awareness, public interest and concern in financial crises. Linked to this is the issue of unemployment, substantial layoffs, downsizings, environmental problems, corporate scandals and unethical misconduct in business. An added view on responsible leadership considers it as a process in which specific parties appreciate the procedural aspects. It goes on to point toward the individual and collective attributes. [Yukl G (2006) Leadership in Organizations. Elsevier, New York] Taking a cue from the trusteeship approach of industrial relations this concept targets that the influencing power of a leadership should not only concentrate on material interest of profitability but also for the good of all. Although a recent concept, it has attracted much attention (Shi \&Ye, 2016), despite that it has failed to concentrate on key issues limiting to theoretical ideas. It goes saying without any deliberation that leadership has been one of the most researched topics in organizational studies, management, and many other related areas hence said to be paramount for key organizational issues such as performance [Howell \& Arolio, 1993], and also for many other individual, group, and organizational indicators [G Wang, Oh Court right \& Colbert,2011].

As we move forward, in this field focus has been primarily on the characteristics and behaviours that in the progression of leadership help to utilize individuals, encourage positive relationships, shore up ethical and moral standards, and fire up well-organized societal dynamics in organizations. Contrary to other ideas, the concept of transformational leadership invigorates interactional-based relationships between the stakeholders, attitudes, values and other personal and professional-type of stimulus [Tal \& Gordon, 2016]. This presupposes that workers progress as professionals and persons, influencing dexterity of leaders [Burns, 1978]. Surprising component in all these cases is that the goodness of leadership, as a prevalent practice is plagued with evil leadership in all sectors and organizations [Pfeiffer, 2015]. Since globalization, dependable social interpretation has been indicating the transformation to responsible leadership, it has caught considerable attention, initially implicit as "a social-relational and ethical phenomenon, occurring as social processes of interaction”. [ Maak and Pless 2006b, p 99] Hence we may contemplate that this approach may be considered to be distinctive from other theories, for the 
reason that its philosophy is rooted in the necessity to maintain a multifaceted and dynamic equilibrium between elements of organization and style of leadership. For accomplishing such challenging objectives, we must maintain an ethical perspective, while assuring the requisites for efficiency and efficacy. [Volgtlin, Patzer and Scherer, 2012] As a fall out, it is likely to have a wider and deeper bearing on numerous outcomes. Ethical leadership predicts outcomes such as perceived effectiveness of leaders, followers' job satisfaction and perseverance, as well as their willingness to report problems to management for combining the macro-view of the business firm with the micro-view of leadership [Martinko MJ, Moss SE, Douglas SC, Borkowski N (2007) Anticipating the inevitable: When leader and member attribution styles clash. Organizational Behaviour and Human Decision Process 104: pp 158-174], which appears to be an avenue linking corporate responsibility, performance of firms with leaders' actions. The traditional and usual relationships between parties, leaders-followers, are not enough for today's network of relationships, thus a more doable approach to leadership is demanded indicating a bias towards responsible leadership. The voids in existing analysis on the subject suggest potential research avenues.

As we progressed, certain factors emerged, showing different research fields on the topic of responsible leadership, ranging from organization's contribution to the evolution of leadership, impact on organizational behaviour, emotional contagion, and development of employees, organizational performance, sexual harassment and future perspectives, roles of responsible leaders.

\section{CRITICAL ISSUES}

Since nineties world has accepted globalization, which has improved the economies, made technological advancement transparent and improved quality control of developing countries. A phenomenon which has caught attention along with this development is the emergence of responsible leadership as a concept. As a part of the research in this paper it is intended to analyze the impact of responsible leadership on organizational behaviour by covering the driving force spear heading responsible leadership, its organizational support, contribution to meeting the aspirations of the stake holders, and consciousness with respect to risk management. With a growing trend of multi-ethnic work force, the attempt has been seen as to how this approach has incorporated the change for better productivity. Changing demography of the work force and introduction of dual income family group has revolutionized application of leadership theories. The concept of responsible leadership predominantly considers the way power is utilized. A rational use of power is selected for improving stakeholder's lives rather than contributing to the purging of individual careers, organizations, economies, and societies. Hence as a net effect they tend to influence organization as a whole and not purely limited to the employees. When we deliberate other side of pervading leadership, its treatment of potentially conflicting set of interests is balanced completely. Thus, it becomes a key theme to recognize, and one which organizations and decision-makers alike should encourage and alert people about. Even though the advancements in leadership theory recommend a generic positive feeling about the goodness of leadership, this practice is plagued with evil leadership in all sectors and organizations [Pfeiffer, 2015]. Contemporary phenomenon on leadership has focused on the characteristics and behaviours that, in this process help to develop individuals, encourage positive relationships, and support ethical, moral standards and take care to stimulate efficient social dynamics in organizations. Responsible leadership assumes this role so that workers evolve as professionals and persons with the passionate contribution of the influencing capacity of leaders in shaping vision, moral values, coherence, inspiration, and ethics.

A paradigm shift is needed for leaders in a conglomerate setting which has been increasingly populated with new notions, concepts, and theories of leadership to bring a more positive impact into human lives. When seen within a large framework all stakeholders that work together with the leader are considered followers, whether they are from inside or outside the organization. Here it assumes characteristic note that responsible leadership as an approach with related leadership theories such as transformational, ethical, servant, authentic leadership, can bring about a confluence resulting in organizational effectiveness. Taking a cue from Boyatzis [Boyatzis Richard Ivy Business Journal January/February 2011, Neuroscience and Leadership: The Promise of Insights] certain leadership characteristics can be considered to kindle responsible leadership. As a result of analysis, it has been seen that old concepts of leader-follower do not engender the desired network of relationship, which demands for a more relational leadership.

It has been generally seen that responsible leadership contributes to building social capital and ultimately develops a sustainable business and common good. Principled leadership is related to selflessness behaviour, integrity and faith in the leader, interactional transparency, and proactive leadership. In this way it is not subsumed by deviations, which is the epitome of responsible leadership, saying that it reveals out comes such as perceived effectiveness of leaders, followers' job satisfaction, dedication, and their willingness to give an account of the problems to management. The common understanding of the dual relationship between leader-subordinates in the organization is considered unsatisfactory for the multitude of relationships between all the agents, leader and followers/stakeholders. Therefore, responsible leadership is understood as a "social-relational and ethical phenomenon, which occurs during social processes of interaction" [Maak and Pless 2006b, p 99]. In that way it designates the quality of life and the organization fine 
tunes with its business interests. It would be prudent to reflect on the competency of responsible leadership in decision making process by exploring and working with various stake holders. By focusing on the interest of employees and other stakeholders this approach can ensure that business results are not more important than social concerns and initiatives by tasking as per the developmental level of the group. It is for sure that as a result strength of team concept will be moderated by the attribution styles of the leaders and the members [Kumar K (2003) Has India Inc. failed in playing the Leadership role? Vikalpa pp 28: 1-14] which is apt for a better leadermember relationship and generating a positive organizational climate for reducing job burnout [Bass BM (1990) Bass and Stogdill's handbook of leadership. Free Press, New York]. With respect to performance of subordinates and manager's ratings of team performance the results did not significantly correlate with what the team members had to say about their own performance in consideration of this leadership approach. At present we have almost a third of the working population as women. Women both as subordinates and in positions of power can be subjected to sexual harassment. This can cause havoc in an organization but can possibly be avoided by responsible leadership.

\section{NEW INSIGHTS}

A responsible leader is obsessed by a values-based vision of the future that goes beyond pure business considerations. All types of leadership do not show signs of responsible decisions, but manifest in specific moments, in the course of which leaders have to make indispensable pronouncements which have a prolonged effect on the people, environment and future of the organization. In that way these key moments reveal the appeal and truthfulness of a leader reconciling with the idea of effectiveness and sense of corporate responsibility, by supporting active citizenship inside and outside the organization. The desire to function as a team close to the stakeholders is well entrenched in this approach to leadership, which can also be seen as the art of building and sustaining societal and moral relationships between business leaders and different stakeholders which is based on a sagacity of justice, a feeling of acknowledgment, judiciousness of mind, discernment of accountability for a wide range of economic, ecological, social, political and human responsibilities.

Liberalization has brought in volatile challenges of business environment. Human resource is one Such attribute which has been found to be a competitive edge. Its impact will be far greater in the future environment considering the rapidity of change in technology and on leadership, organizational behaviour. A related concern is that countries with less political stability have high volatile business environment which makes leadership approach more challenging. How does a responsible leader translate the mission in such a scenario? Preparing for and embracing that change by investing in conscientious leadership is the best way to meet these challenges head on. For this it is necessary that communication and networking is given adequate emphasis. As organizations are becoming more heterogeneous in terms of gender, age, race, ethnicity, and sexual orientation leader must ensure that unfair discrimination is eliminated. From organizational behaviour outlook inculcating group cohesion is an important aspect imploding that survival of an organization is not only because of productivity but also as to how well it fits with the environment. Emotions are disruptive hence a manger must identify and modify emotions. In order to improve employees' moods leader should use humour and give employees small token of appreciation which can be monetary as well as nonmonetary for work well done. Intensity is the element when channelled in the direction that benefits organization leads to favourable job-performance outcomes. This implies that employee participation can increase the employee productivity, commitment to work goals, motivation and job satisfaction. What responsible leadership tries is generation $\mathrm{X}$ context is aim at making employees perceive their job roles the same way the leader sense their roles. The modern concept to shift from working alone to teams require employees to cooperate with others, brazen out differences, and sublimate personal interests for the good of the team. In such a scenario it is thrust upon the responsible leadership to understand these challenges and continuously get to better ways for running business.

\section{METHODOLOGY}

From such a view point it is necessary for a researcher to conduct a detailed analysis of the supported relationship between responsible leadership and organizational behaviour. For this purpose, a questionnaire with the center of attention as to who are the stakeholders, their modus of operandi with each group and dovetailing the shareholder interests with stakeholder interests by the leader was framed. By case study method on the methodology adopted by responsible leaders on various situations and the peculiarities it was possible to obtain a realistic feedback. From the interviews held on the responsible leadership behaviour it was possible to categorize them into three groups namely, epitome of stakeholder's concern, practical outlook and professional approach. In that process the researcher was able to bring into consideration fifty characteristics which included nine of personalized scales, twelve on situational leadership, and four items for evaluating responsible leadership. It was also considered to establish a correlation between this style and corporate performance. There after these fifty items were launched on Qualtrics and provided to 400workingpersonnel holding corporate positions from lower to higher levels of management. A convenience sampling technique was adopted considering the willingness of the respondents and propinquity. 212 responded to the survey with $70: 30$ ratio favoring male respondents. Responses were assessed using SPSS and EFA and results indicated that the three correlated 
factor model provided the most economical fit to the data, supporting the assertion that responsible leadership has a definite impact on organizational behaviour.

\section{ASSERTIONS}

Human relation approach to management by Elton Mayo and other scientists was the steppingstone for the emergence of responsible leadership and impetus was given by globalization. Thereafter with rapid technological advancement it has rather become a deep-seated requisite for companies to continuously innovate and go forward. If they fail, unfortunately, there will be no tomorrow for them. Employees or teams are empowered based on the maturity level for doing well rather than avoiding harm by this approach. As a result, it is a step ahead of MBO ensuring enhanced performance by improving efficiency and effectiveness. In the modern concept of multiethnic staffing to propel outcomes responsible leadership can emerge as the game changer due to it flexible approach. Possibly the outcome alone is not only the deciding factor, but one has to consider the emotive contagion effect and deep rooted diversity in employees. Employee involvement is an essential aspect of this approach which helps in attracting and retaining talent.

\section{IMPLICATIONS FOR FUTURE}

It goes without much assertion to state that future business would hinge on responsible leadership as it eliminates influence of various types of bias in decision making. The aspirations of new generation employees are to progress their career and being future ready for employment while being engaged in job. This aim will receive fillip as fallout of this approach. Responsible leadership presupposes two cultural characteristics; willingness to accept a moderate degree of risk and concern with performance. As anticipated the focus would be to generate teamwork removing status inequity, eliminate diversity and promoting cohesiveness. Modern concept of virtual team by its innovative staffing would need responsible leadership. In his genre-defining book titled "Leadership", James Macgregor Burns made striking mention that a leader's qualities and his character will make a great difference to organizational effectiveness. According to Burns, civilization depends not only on problem solvers but those who take the society to a higher level of morality and motivation. According to Mintzberg [Mintzberg H (1998) Covert leadership: Notes on managing professionals. Harvard business review76: pp140-148], leaders irrespective of the approach share one personality trait in common which is the passion to lead. But various styles of leadership have their own multiple advocates and acolytes and do not have dearth of experts or sophistication of approaches. Despite that no consensus has been reached on which style of leadership is appropriate. Even though individual qualities of leaders do matter, the effectiveness of leadership is increasingly believed to depend on the situational and contextual factors in which the leaders are working.

Methodology of leadership and the eventual outcome of the task have very strong effects on the perception of appropriateness of leadership style. Interpersonal, cognitive and political skills, technical proficiency and project management dexterity are vital for effective leadership [Rosier RH (1997) the competency model handbook. Linkage, Lexington, MA]. Most importantly are the aspects of organizing skills, envisioning success and ability to achieve social integration. Spanning the external environment to ensure that their team efficiently achieves the goals of the organization at the same time maintaining a cohesive team is also one of the essential qualities of a leader. They should seek employee support in terms of sharing information for monitoring the organization and its goals, by creating transparent systems and a supportive culture. When few business organizations from all over the world were studied emotional competencies were also found to be largely responsible for effective performance [Rowley J, Mayfield MR, Kopf J (1998) Effects of leader motivating language on subordinate performance and satisfaction. Human Resource management 37: pp 235-248]. Subordinates who are collectivists and those who are individualists are motivated creatively by different leadership styles adopted by their superiors. Collectivists prefer transformational leaders whereas the others prefer transactional leaders.

Leaders having high emotional intelligence seek challenges and they perceive them as opportunities for development not only for the individual but also for the organization [Punia BK (2005) Impact of Demographic variables on Emotional Intelligence and Leadership behavior. Journal of Organizational Behavior 2: pp7-22]. Conscientiousness, openness to experience and agreeableness have been found to be an essential attribute for responsible leadership. They were found to be correlated and the correlations were $0.28,0.08$, and 0.24 , respectively. Another important observation was that more open a person is to new suggestions it likely that he will make an effective leader. Tact is essential but need for affiliation, being modest to a scale, sensitivity, altruism is positive attributes. Members perceived a poor leader-member relation mostly when they were biased toward optimistic attributions for the negative outcomes. The Leaders attributed internal and pessimistic attributions for negative outcomes of members. If a leader's representativeness of a group is high, he receives more trust and will be perceived as more effective by his followers even if he fails to achieve a maximum goal, but not if he fails to achieve a minimal goal. 


\section{CONCLUSION}

In conclusion, the future business environment being volatile due to politico-economic factors does translate its requirement to responsible leadership for organizational effectiveness. The need for addressing the transient challenges by the evolution of multi-ethnic work force and global or multi country business approach demands wider acceptability of responsible leadership approach. Findings of the study and the responses received from participants in the survey do find attributable relationship between responsible leadership and organizational behaviour. A case which can be highlighted of the recent past is the complete transformation of Damodar Valley Corporation by the CEO Mr. Luker from a loss-making firm to a profitable organization by responsible leadership and employee empowerment. The future maintains that interpersonal, cognitive and project management skills, along with ability to achieve social integration by creating transparent systems ensures achievement of organizational goals. Emotional intelligence and high emotional quotient are attributes of a leader which contributes to responsible decisions. Virtual organization is the modern organizational structure which is typically a small core organization that outsources its major business functions. [RE Mills and CC Snow, "The New Network Firm: A spherical Structure Built on Human Investment Philosophy” Organizational Dynamics (Spring 1995) pp 94-96] In structural terms, it is highly centralized outsourcing all primary management functions which implies flexibility and have team members geographically dispersed. Here a responsible leadership presence can be constructive in case it reinforces the objective of the organization and facilitates communication.

\section{REFERENCES}

[1] EH Schein, Role of Founder in creating organizational culture" Organizational Dynamics (Summer 1983), 13-18.

[2] Yukl G. (2006). Leadership in Organizations. Elsevier, New York.

[3] Martinko MJ, Moss SE, Douglas SC, Borkowski N. (2007). Anticipating the inevitable: When leader and member attribution styles clash. Organizational Behavior and Human Decision Process. 104, 158-174

[4] Boyatzis [Boyatzis Richard Ivy Business Journal January/February 2011, Neuroscience and Leadership: The Promise of Insights]

[5] Kumar K. (2003). Has India Inc. failed in playing the Leadership role? Vikalpa, 28, 1- 14

[6] Bass BM, (1990) Bass and Stogdill's handbook of leadership. Free Press, New York.

[7] Mintzberg H. (1998). Covert leadership: Notes on managing professionals. Harvard business review. 76,140-148.

[8] Rosier RH. (1997). the competency model handbook. Linkage, Lexington, $M A$.

[9] Rowley J, Mayfield MR, Kopf J. (1998). Effects of leader motivating language on subordinate performance and satisfaction. Human Resource management, 37, 235-248.

[10] Punia BK. (2005). Impact of Demographic variables on Emotional Intelligence and Leadership behavior. Journal of Organizational Behavior. 